\title{
Delta-aminolevulinic Acid Transport by Intestinal and Renal Peptide Transporters and Its Physiological and Clinical Implications
}

\author{
Frank Döring, ${ }^{*}$ Judith Walter, ${ }^{\star}$ Jutta Will, ${ }^{*}$ Melanie Föcking, ${ }^{*}$ Michael Boll, ${ }^{\star}$ Salah Amasheh, ${ }^{\ddagger}$ Wolfgang Clauss, ${ }^{\ddagger}$ \\ and Hannelore Daniel* \\ *Institute of Nutritional Sciences and ${ }^{\ddagger}$ Institute of Animal Physiology, University of Giessen, 35392 Giessen, Germany
}

\begin{abstract}
Delta-aminolevulinic acid (ALA) is the precursor of porphyrin synthesis and has been recently used in vitro and in clinical studies as an endogenous photosensitizer for photodynamic therapy in the treatment of various tumors. For this purpose, ALA is given topically, systemically, or orally. When administered by the oral route, it shows excellent intestinal absorption. ALA is also efficiently reabsorbed in the renal proximal tubule after glomerular filtration. However, the pathways and mechanisms for its transmembrane transport into epithelial cells of intestine and kidney are unknown. Here we demonstrate that ALA uses the intestinal and renal apical peptide transporters for entering into epithelial cells. Kinetics and characteristics of ALA transport were determined in Xenopus laevis ooyctes and Pichia pastoris yeast cells expressing either the cloned intestinal peptide transporter PEPT1 or the renal form PEPT2. By using radiolabeled ALA and electrophysiological techniques in these heterologous expression systems, we established that: (a) PEPT1 and PEPT2 translocate ${ }^{3} \mathrm{H}$-ALA by saturable and $\mathrm{pH}$-dependent transport mechanisms, $(b)$ that ALA and di-/tripeptides, but not GABA or related amino acids, compete at the same substrate-binding site of the carriers, and (c) that ALA transport is electrogenic in nature as a consequence of $\mathrm{H}^{+} / \mathrm{ALA}$ cotransport. Reverse transcriptase-PCR analysis performed with specific primers for PEPT1 and PEPT2 in rabbit tissues demonstrates that, in particular, the PEPT2 mRNA is expressed in a variety of other tissues including lung, brain, and mammary gland, which have been shown to accumulate ALA. This suggests that these tissues could take up the porphyrin precusor via expressed peptide transporters, providing the endogenous photosensitizers for efficient photodynamic therapy. (J. Clin. Invest. 1998. 101: 2761-2767.) Key words: delta-aminolevulinic acid • peptide transporters - heterologous expression - photodynamic therapy
\end{abstract}

\footnotetext{
Address correspondence to Hannelore Daniel, Institute of Nutritional Sciences, University of Giessen, Wilhelmstrasse 20, 35392 Giessen, Germany. Phone: 641-99-39042. FAX: 641-99-39049. E-mail: hannelore.daniel@ernaehrung.uni-giessen.de

Received for publication 2 October 1997 and accepted in revised form 9 April 1998.
}

J. Clin. Invest.

(C) The American Society for Clinical Investigation, Inc. 0021-9738/98/06/2761/07 \$2.00

Volume 101, Number 12, June 1998, 2761-2767

http://www.jci.org

\section{Introduction}

Di- and tripeptides, as well as a number of $\beta$-lactam antibiotics, are taken up rapidly into epithelial cells of intestine and kidney by specific apical peptide transporters encoded by the pept 1 (intestine) and pept 2 (kidney) genes. The gene products are transmembrane carrier proteins that catalyse electrogenic peptide transport by coupling of substrate translocation to the cotransport of $\mathrm{H}^{+} / \mathrm{H}_{3} \mathrm{O}^{+}$with the transmembrane electrochemical proton gradient providing the driving force. Whereas the intestinal transporter form represents a low affinity/high capacity system, the renal transporter shows generally a higher substrate affinity but lower maximal transport capacity. The cDNAs of these transporters have been cloned from cDNA libraries of intestine and kidney of rabbit, human, and rat (1-7). Both transporter types have been analyzed with respect to their operational mode by expression in Xenopus oocytes, HeLa cells, or the methylotropic yeast Pichia pastoris (4, 5, 8-12). At the amino acid level, these membrane proteins show some homologies to peptide transporters isolated from bacteria, fungi, and plants, and form the so-called PTR family of proton-dependent peptide transporters (13). Recently, it has been demonstrated that in prokaryotic organisms such as Salmonella typhimurium or Escherichia coli, dipeptide permeases mediate the transport of delta-aminolevulinic acid (ALA) ${ }^{1}$ into the cells and that this transport pathway is shared by dipeptides $(14,15)$. In contrast, uptake of ALA into eukaryotes like Saccharomyces cerevisiae was found to be mediated by a specific $\gamma$-aminobutyric acid permease (16). In view of the structural similarities of the PTR-family proteins, we investigated whether the cloned mammalian epithelial peptide transporters PEPT1 and PEPT2 are capable of transporting ALA.

There is a growing interest in the biokinetics and metabolism of ALA, as the compound has been successfully used in treating a variety of tumors by photodynamic therapy $(17,18)$. ALA serves as the precursor for cellular porphyrin synthesis, which is usually tightly regulated by a feedback loop at the level of the ALA synthetase. However, when ALA is provided to the cell directly, porphyrins accumulate within the cells above normal levels, allowing efficient photoactivation that can induce cell death $(19,20)$. For photodynamic therapy approaches, ALA is administered either topically, systemically, or orally $(21,22)$. When ALA is given by the oral route, it shows high oral availability and rapid increases in the circulating plasma level (18). Specific accumulation in intestinal epithelial cells after oral administration of ALA suggests that an efficient intestinal transport system is involved in its delivery (23). On the other hand, plasma levels of ALA are affected by its renal clearance. Studies in rats have established that after

1. Abbreviations used in this paper: ACA, delta-aminolevulinic acid; cRNA, complementary RNA; I-V, current voltage; RT-PCR, reverse transcriptase-PCR. 
glomerular filtration ALA is taken up into cells of the proximal tubule against a concentration gradient $(24,25)$, suggesting an active transport mechanism for this zwitterionic compound.

Identifying the molecular mechanisms underlying the intestinal absorption of ALA and its renal reabsorption could significantly increase our knowledge on the parameters effecting the pharmacokinetics and -dynamics of the compound. Moreover, its selective entry and accumulation in certain cells, which provides a basis for photodynamic therapy applied to neoplastic tissues and normal cells, needs to be resolved. On basis of the observations that certain dipeptide permeases of prokaryotic organisms can translocate ALA, we investigated whether the mammalian peptide transport systems PEPT1 and PEPT2 expressed in intestine and kidney also accept ALA as a substrate. Demonstration of ALA transport mediated by PEPT1 and PEPT2 and the characterization of the underlying transport mechanisms were carried out in two different heterologous expression systems.

\section{Methods}

Peptides and peptidomimetics were purchased from Sigma. ${ }^{3} \mathrm{H}$-Aminolevulinic acid hydrochloride $\left({ }^{3} \mathrm{H}\right.$-ALA; specific activity $\left.2 \mathrm{Ci} \cdot \mathrm{mmol}^{-1}\right)$ was purchased from Du Pont NEN (Bad Homburg, Germany). Custom-synthesized ${ }^{3} \mathrm{H}$-D-Phenylalanyl-L-alanine (3H-D-Phe-ALA) with a specific activity of $9 \mathrm{Ci} \cdot \mathrm{mmol}^{-1}$ was obtained from Zeneca (Cleveland, UK).

\section{Studies in Xenopus laevis oocytes expressing PEPT1} or PEPT2

Expression of the transporters and flux studies. Surgically removed oocytes were separated by collagenase treatment and handled as described previously $(1,2)$. Individual oocytes were injected with $50 \mathrm{nl}$ of water (controls) or $50 \mathrm{nl}$ of RNA solution containing $5 \mathrm{ng}$ of the transporters complementary RNA (cRNA). All flux studies were performed after $3 \mathrm{~d}$ by incubation of oocytes in a buffer composed of $100 \mathrm{mM} \mathrm{NaCl}, 3 \mathrm{mM} \mathrm{KCl}, 1 \mathrm{mM} \mathrm{CaCl}, 1 \mathrm{mM} \mathrm{MgCl}_{2}, 5 \mathrm{mM}$ Hepes/ Tris at $\mathrm{pH} 7.4$, or $5 \mathrm{mM} \mathrm{Mes/Tris} \mathrm{at} \mathrm{pH} \leq 6.5$. Uptake of ${ }^{3} \mathrm{H}$-ALA and ${ }^{3} \mathrm{H}$-D-Phe-L-Ala was linear over a time period of at least $40 \mathrm{~min}$, both at low $(0.04 \mathrm{mM})$ and high $(10 \mathrm{mM})$ substrate concentrations. For all studies, an incubation time of $10 \mathrm{~min}$ was chosen to represent initial rate influx.

Electrophysiology. The two-electrode voltage clamp technique was applied to characterize responses in inward current to substrate addition in oocytes injected with $5 \mathrm{ng}$ transporter cRNA as described previously $(1,2)$. Steady-state current voltage (I-V) relationships were measured in a buffer composed of $100 \mathrm{mM} \mathrm{NaCl}$ (or CholineCl), $3 \mathrm{mM} \mathrm{KCl}, 1 \mathrm{mM} \mathrm{CaCl}_{2}, 1 \mathrm{mM} \mathrm{MgCl}_{2}, 5 \mathrm{mM}$ Mes/Tris, $\mathrm{pH}$ 6.0 , in the absence and the presence of ALA and other substrates with water-injected oocytes serving as controls. Membrane potential in oocytes was held at $-60 \mathrm{mV}$ and stepped symmetrically to test potentials from -150 to $+50 \mathrm{mV}$ by $500 \mathrm{~ms}$ rectangular voltage pulses, and current recordings were obtained during the last $100 \mathrm{~ms}$.

\section{Studies in P. pastoris expressing PEPT1 or PEPT2}

Cell culture, $P$. pastoris strains, and induction of PEPT1/PEPT2 expression. P. pastoris strains were cultured as described in the manual Version E of the Pichia expression kit (Invitrogen, San Diego, CA). The construction of the PEPT1/2 expressing strains and the isogenic control strain (GS-pPIC3L) has been described previously (12) and submitted for publication (Döring, F., T. Michel, A. Rösel, M. Nikolaus, and H. Daniel). In the transgenic yeast strains, GS-PepT1 and GS-PepT2, the PepT1/2 cDNAs were under the transcriptional control of the AOX1 promotor, which is inducible by methanol. For induction of PEPT1/2 expression, cells were initially grown in a glyc- erol-containing medium ( $1.34 \%$ yeast nitrogen base, $4 \times 10^{-5} \%$ biotin and $1 \%$ glycerol), and then switched to a medium containing $1 \%$ methanol. Uptake of ${ }^{3} \mathrm{H}-\mathrm{D}-\mathrm{Ph}$-L-Ala or ${ }^{3} \mathrm{H}-\mathrm{ALA}$ was measured 18-36 $\mathrm{h}$ after induction of the PEPT1/2 expression.

Transport assay in yeast. Uptake measurements were performed at $22-24^{\circ} \mathrm{C}$ by using a rapid filtration technique with Schleicher \& Schuell filters (ME 25 type, $0.45 \mu \mathrm{m}$ pore size) as described previously (12). Uptake was initiated by rapidly mixing $10 \mu \mathrm{l}$ of cell suspension with $40 \mu \mathrm{l}$ of $50 \mathrm{mM}$ phosphate puffer containing $0.1 \mu \mathrm{Ci}$ of ${ }^{3} \mathrm{H}$-ALA or ${ }^{3} \mathrm{H}$-D-Phe-L-Ala, respectively. Competition studies used the following selected compounds: glycine, glutamate, lysine, GABA, porphobilinogen, Gly-Gly, tri-Gly, Gly-Gln, and cefadroxil.

Reverse transcriptase (RT)-PCR analysis. Total RNA from rabbit tissues was isolated by the acid guanidinium thiocyanate/phenol/chloroform extraction procedure as described previously (2). First-strand cDNA, prepared from $5 \mu \mathrm{g}$ total RNA using PEPT1 (b11), PEPT2 (b12), and GAPDH (b21) specific primers, was amplified by PCR using primers (f11 and b11 for PEPT1; f12 and b12 for PEPT2, f21 and b21 for GAPDH) derived from the predicted extracellular loop between the 9. and 10. transmembrane domain of PEPT1 and PEPT2. PCR amplification was performed for 35 cycles with $94^{\circ} \mathrm{C}$ denaturation for $1 \mathrm{~min}, 55^{\circ} \mathrm{C}$ annealing for $1.5 \mathrm{~min}$, and $72^{\circ} \mathrm{C}$ extension for 1.5 min. Primers f11 and b11 representing the nucleotides 1154-1169 (f11: 5'-CTCTTCCTGTCTTCCC-3') and 1544-1529 (b11: 5'-CTGGCATTGTAGCTGG-3') of the protein-coding region of PEPT1. Oligonucleotides f12 and b12 representing the nucleotides 1154-1175 (f12: 5'-CTAGCATGCCTGGCATTTGCAG-3') and 1886-1866 (b12: 5'-CCTGTGACAGAGAACATGACC-3') of the open reading frame of PEPT2. Primers $\mathrm{f} 21$ and $\mathrm{b} 21$ representing the nucleotides 558-579 (f21: 5'-GACCACAGTCCATGACATCACT-3') and 1010-990 (b21: 5'-TCCACCACCCTGTTGCTGTAG-3') of the open reading frame of GAPDH.

Calculations and statistics. All calculations (linear as well as nonlinear regression analysis) were performed by using INPLOT (GraphPAD, Los Angeles, CA). For each variable, at least three independent experiments (5-8 oocytes, two yeast preparations) were carried out. Data are given as the mean \pm SEM. Significance of differences between the uptake rates and constants calculated were determined by a nonpaired $t$ test.

\section{Results}

ALA influx into the transgenic yeast strains. P. pastoris cells expressing PEPT1 or PEPT2 showed a dramatic increase in ALA influx $\left(0.11 \pm 0.02 \mathrm{nmol} \cdot 10 \mathrm{~min}^{-1} \cdot \mathrm{OD}^{-1}\right.$ for PEPT1 and $0.1 \pm 0.01 \mathrm{nmol} \cdot 10 \mathrm{~min}^{-1} \cdot \mathrm{OD}^{-1}$ for PEPT2) compared to wild-type cells $\left(0.001 \pm 0.001 \mathrm{nmol} \cdot 10 \mathrm{~min}^{-1} \cdot \mathrm{OD}^{-1}\right)$ when incubated with $5 \mu \mathrm{M}{ }^{3} \mathrm{H}$-ALA at $\mathrm{pH}$ 7.0. That this increase is a consequence of induction of saturable carrier-mediated transport processes is demonstrated by Michaelis Menten type kinetics of influx as a function of ALA concentration (Fig. 1a) for both transporters. The apparent $\mathrm{K}_{0.5}$ value for ALA influx mediated by PEPT1 as derived from the Eadie-Hofstee transformations (Fig. $1 b$ ) was $0.275 \pm 0.037 \mathrm{mM}$ and $0.226 \pm 0.019$ $\mathrm{mM}$ for that mediated by PEPT2. The apparent $\mathrm{V}_{\max }$ in case of PEPT1 was $3.99 \pm 0.1 \mathrm{nmol} \cdot 10 \mathrm{~min}^{-1} \cdot \mathrm{OD}^{-1},\left(\mathrm{r}^{2}=0.985\right)$ and in case of PEPT2 was $2.82 \pm 0.07 \mathrm{nmol} \cdot 10 \mathrm{~min}^{-1} \cdot \mathrm{OD}^{-1},\left(\mathrm{r}^{2}=\right.$ 0.991). That the induced transport activity for ALA is shared by dipeptides was demonstrated by cross-inhibition studies with either D-Phe-L-Ala and ALA serving as substrates or competitors (Fig. 1, $c$ and $d$ ). Influx of D-Phe-L-Ala was determined in the absence and presence of increasing concentrations of ALA, and the $\mathrm{EC}_{50}$ values obtained for inhibition reflected the apparent $\mathrm{K}_{0.5}$ values for ALA influx. When D-Phe-L-Ala served as the competitor of ALA uptake, its $\mathrm{EC}_{50}$ 


\section{Pichia pastoris cells}
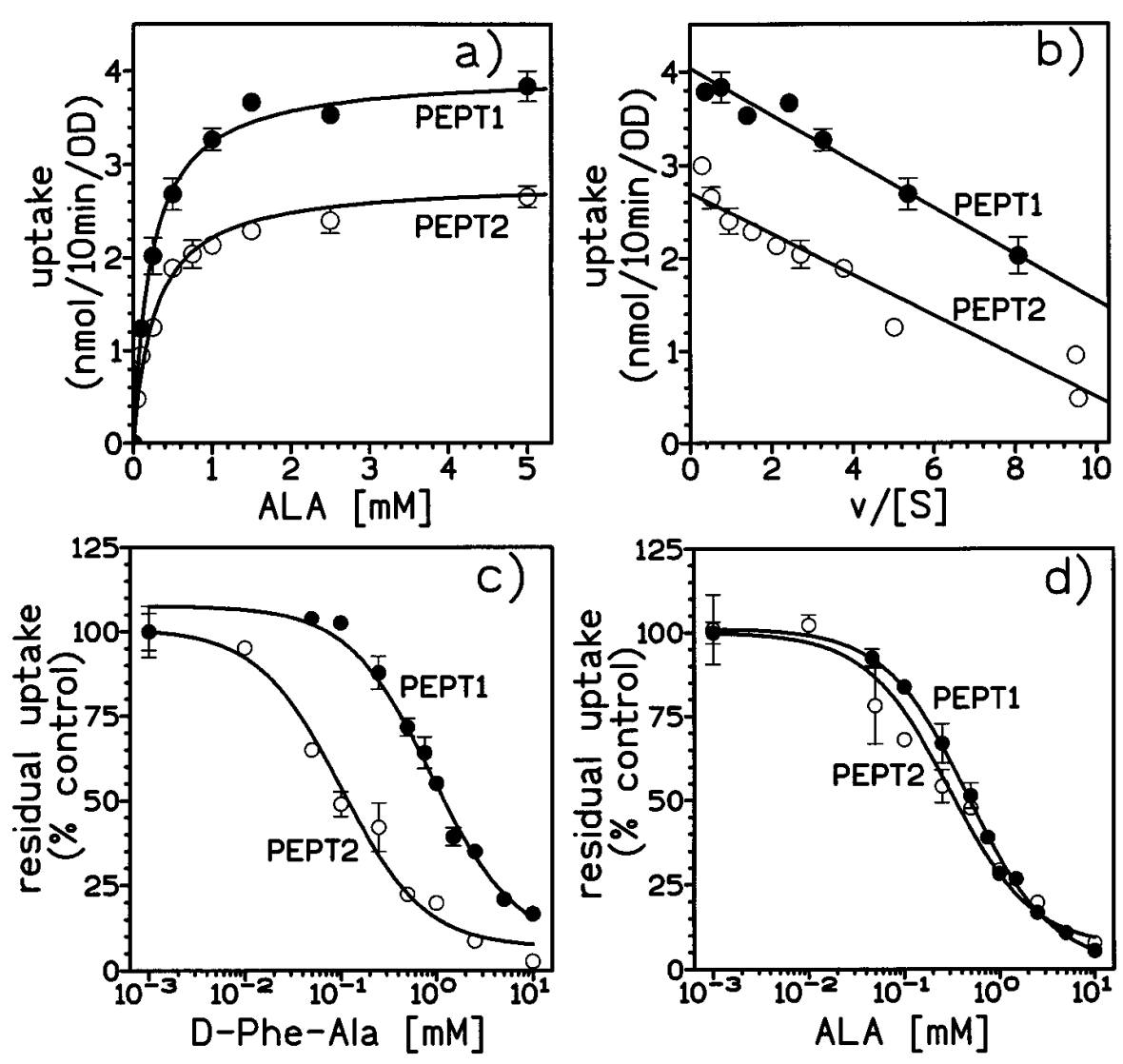

Figure 1. Characterization of ALA uptake into P. pastoris expressing PEPT1 or PEPT2. (a) ALA uptake as function of substrate concentration. Influx of ${ }^{3} \mathrm{H}$-ALA $\left(2 \mu \mathrm{Ci} \mathrm{ml} l^{-1}\right)$ into the $P$. pastoris control cells or cells expressing either PEPT1 $(\bullet)$ or PEPT2 $(\bigcirc)$ was measured over $10 \mathrm{~min}$ of incubation, at $\mathrm{pH} 7.0$, in the presence of increasing concentrations of unlabeled substrate $(0.001-5 \mathrm{mM})$. The uptake rates in control cells were substracted from the corresponding uptake rates in PEPT1- or PEPT2-expressing cells. Uptake rates represent the mean \pm SEM of two independent experiments performed in triplicate. $(b)$ Transport rates were transformed according to Eadie-Hofstee and kinetic constants were derived by linear regression analysis by the least-squares method. ( $c$ and $d$ ) Mutual cross-inhibition with D-Phe-L-Ala (c) or ALA $(d)$ as competitors. Uptake of $5 \mu \mathrm{M}^{3} \mathrm{H}$-ALA $\left(2 \mu \mathrm{Ci} \cdot \mathrm{ml}^{-1}\right)$ or $5 \mu \mathrm{M}$ ${ }^{3} \mathrm{H}$-D-Phe-L-Ala $\left(2 \mu \mathrm{Ci} \cdot \mathrm{ml}^{-1}\right)$ into $P$. pastoris expressing PEPT1 or PEPT2 was measured for $10 \mathrm{~min}$ of incubation at $\mathrm{pH}$ 7.0, in the presence of increasing concentrations (0.001-10 mM) of D-Phe-L-Ala or ALA. Transport rates of D-Phe-L-Ala or ALA into control cells were subtracted. Data are presented as mean \pm SEM for the residual uptake in the presence of competitors as percentage of control uptake. The $\mathrm{EC}_{50}$ values were derived by the least-squares method based on a competition curve with one component ( $\mathrm{r}^{2}$ in all cases, $\geq 0.98$ ). value in case of PEPT1 was $0.521 \pm 0.056 \mathrm{mM}$ and in case of PEPT2 was $0.165 \pm 0.022 \mathrm{mM}$. These apparent affinities are comparable to the $\mathrm{K}_{0.5}$ values for D-Phe-L-Ala influx, as previously reported for PEPT1 and PEPT2 when expressed in $P$. pastoris or $X$. laevis oocytes $(1,2,12)$. Next, we determined the potency of selected peptides, amino acids, peptidomimetics, and the ALA analogues GABA and porphobilinogen for inhibition of ${ }^{3} \mathrm{H}$-ALA influx into PEPT1/2 expressing cells. As shown in Table I, di-Gly, tri-Gly, and the $\beta$-lactam antibiotic cefadroxil, but not GABA, porphobilinogen, and the amino acids glycine, glutamate, and lysine were capable to inhibit ${ }^{3} \mathrm{H}$ ALA transport significantly. Based on these studies on ALA influx and the mutual cross-inhibition by dipeptides in the transgenic $P$. pastoris, we conclude that ALA and dipeptides share the same transport pathways. To analyze in more detail the characteristics of ALA transport mediated by PEPT1 and PEPT2, we used Xenopus oocytes that allow the expressed transport activity to be assessed by tracer flux studies and electrophysiology.

ALA influx into oocytes expressing PEPT1 or PEPT2. As shown in Fig. $2 c$, ALA uptake $(5 \mu \mathrm{M})$ into oocytes as a function of $\mathrm{pH}$ displayed a pronounced $\mathrm{pH}$ dependency with a $\mathrm{pH}$ optimum at 5.5-6.0. Whereas shifting buffer $\mathrm{pH}$ from 8.0 to 6.0 increased the influx mediated by PEPT1 about fourfold, the PEPT2-mediated uptake was increased almost 15 -fold. Waterinjected control oocytes did not show any $\mathrm{pH}$-dependent ALA transport. As in the transgenic $P$. pastoris cells, uptake of radiolabeled ALA into oocytes displayed saturation kinetics when
Table I. Specificity of Substrate Interaction with ${ }^{3} H-A L A$ uptake into P. pastoris Expressing PEPT1 or PEPT2

\begin{tabular}{lcc}
\hline \multicolumn{1}{c}{ Competitor } & Uptake PEPT1 & Uptake PEPT2 \\
\hline & $\%$ of control & $\%$ of control \\
None & $100 \pm 5.0$ & $100 \pm 2.7$ \\
Glycine & $107 \pm 14$ & $102 \pm 11$ \\
Gly-Gly & $10.3 \pm 0.6^{*}$ & $6.2 \pm 0.8^{*}$ \\
Gly-Gly-Gly & $12.9 \pm 0.7^{*}$ & $6.2 \pm 1.0^{*}$ \\
Cefadroxil & $35.1 \pm 3.9^{*}$ & $1.5 \pm 0.4^{*}$ \\
ALA & $17.3 \pm 0.6^{*}$ & $26.4 \pm 0.9^{*}$ \\
Porphobilinogen & $86.7 \pm 4.4$ & $73.5 \pm 4.2$ \\
GABA & $94.3 \pm 8.4$ & $97.3 \pm 1.9$ \\
Lysine & $82.9 \pm 9.8$ & $101 \pm 14.3$ \\
Glutamate & $89.4 \pm 1.7$ & $93.7 \pm 3.7$ \\
& &
\end{tabular}

* $P \leq 0.001$ compared to uptake rates in the absence of competitor (nonpaired $t$ test). Uptake of $5 \mu \mathrm{M}{ }^{3} \mathrm{H}$-ALA $\left(2 \mu \mathrm{Ci} \cdot \mathrm{ml}^{-1}\right)$ into PEPT1 or PEPT2 expressing $P$. pastoris cells was measured for $10 \mathrm{~min}$ of incubation at $\mathrm{pH} 7.0$, in the absence or presence of $1 \mathrm{mM}$ of competitors. Uptake rates of ${ }^{3} \mathrm{H}$-ALA into control cells were subtracted. Data are presented as mean \pm SEM for the residual uptake rates compared to control uptake in the absence of inhibitors (\% of control). Control values for uptake of ${ }^{3} \mathrm{H}$-ALA were $0.12 \pm 0.015 \mathrm{nmol} \cdot 10 \mathrm{~min}^{-1} \cdot \mathrm{OD}^{-1}$ (PEPT1) and $0.1 \pm 0.02 \mathrm{nmol} \cdot 10 \mathrm{~min}^{-1} \cdot \mathrm{OD}^{-1}(P E P T 2)$, respectively. Data represent the mean \pm SEM of two independent experiments performed in triplicate. 
determined at $\mathrm{pH} 6.0$ as a function of ALA concentration (Fig. $2, a$ and $b$ ). Although apparent $\mathrm{V}_{\max }$ values were quite different for PEPT1 $\left(1.5 \pm 0.097 \mathrm{pmol} \cdot 10 \mathrm{~min}^{-1} \cdot\right.$ oocyte $\left.^{-1}\right)$ and PEPT2 $\left(0.267 \pm 0.009 \mathrm{pmol} \cdot 10 \mathrm{~min}^{-1} \cdot\right.$ oocyte $\left.^{-1}\right)$ in oocytes, apparent $\mathrm{K}_{0.5}$ values were similar to that obtained in the yeast expression system with 0.394 $\pm 0.073 \mathrm{mM}$ (PEPT1) and $0.227 \pm 0.029 \mathrm{mM}$ (PEPT2). In both expression systems, ALA therefore displayed similar affinities for interaction with the substrate-binding sites on PEPT1 and PEPT2. This is unusual as most of the dipeptides possess considerably higher substrate affinities for PEPT2 than PEPT1 when assayed under identical experimental conditions $(9,10)$. That these phenotypical differences in the kinetics of the two transporter isoforms are still present when a normal dipeptide serves as a substrate or competitor is shown in Fig. $2 d$. With ALA as a substrate, the dipeptide Gly-Gln revealed an $\mathrm{EC}_{50}$ value for inhibition in case of PEPT1 of $0.281 \pm 0.020 \mathrm{mM}$, and in case of PEPT2 of $0.028 \pm 0.003 \mathrm{mM}$. Similarly in the competition experiment shown in Fig. $1 c$ in P. pastoris, a fivefold difference in apparent D-Phe-L-Ala affinity was obtained by comparison between PEPT1 and PEPT2. ALA, therefore, seems to represent a unique substrate that displays almost the same affinity for the intestinal and the renal transporter form.

As has been established by electrophysiological techniques, both epithelial peptide transporters operate in an electrogenic mode in voltage-clamped oocytes by generating inwardly directed currents in the presence of proton and substrate gradients $(9,10)$. The positive inward current caused by substrate translocation is a consequence of a substrate-mediated proton translocation, that in case of zwitterionic substrates, occurs with a 1:1 proton/dipeptide flux coupling ratio $(8,11)$. To investigate whether the transporters also operate electrogenically with ALA serving as a substrate, we applied the two-electrode voltage clamp technique to oocytes expressing PEPT1 and PEPT2. As demonstrated in Fig. $3 a$, for oocytes perfused with $2.5 \mathrm{mM}$ Gly-Gln, ALA, GABA, glutamate, or lysine at pH 6.0, only ALA and Gly-Gln induced significant inward currents. When $\mathrm{NaCl}$ in the incubation medium was replaced by CholineCl, ALA-induced inward currents remained unaffected (Fig. $3 a$ ). Maximal currents evoked by ALA in the case of PEPT1 exceeded those of PEPT2 several times, similar to the differences in the $\mathrm{V}_{\max }$ values obtained in the flux studies with ALA serving as substrate (Fig. $2 a$ ). When ALA-induced currents were determined as a function of membrane potential, we obtained I-V curves (Fig. $3 b$ ) characteristic for PEPT1 and PEPT2 and almost identical to those reported for Gly-Gln $(9,10)$. The two-electrode voltage clamp studies clearly established that PEPT1 and PEPT2 mediate electrogenic protondependent transport of the zwitterionic ALA with similar characteristics as that obtained for dipeptides.

\section{Xenopus laevis oocytes}
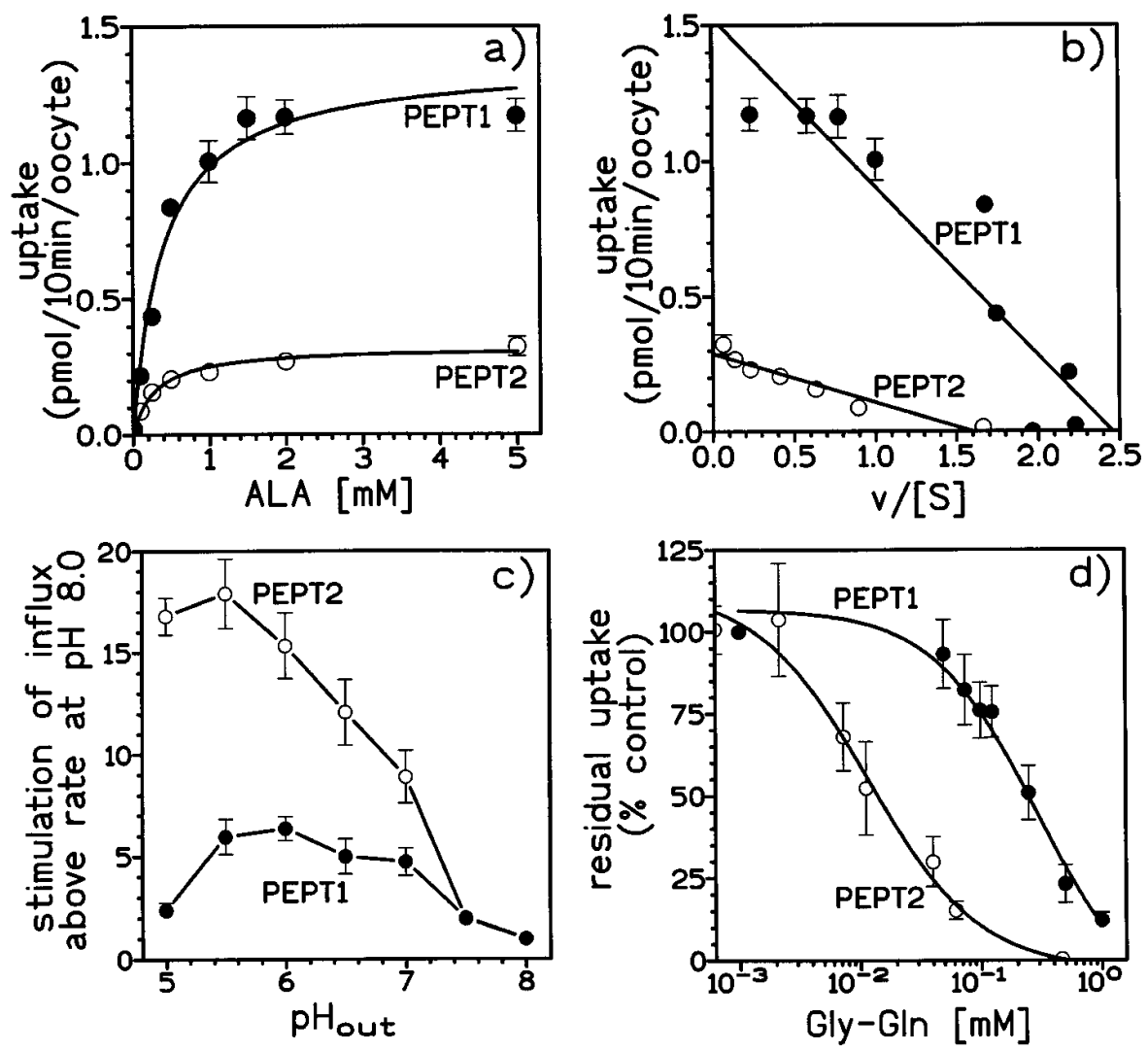

Figure 2. Characterization of ALA uptake into Xenopus oocytes expressing PEPT1 or PEPT2. (a) ALA uptake as a function of substrate concentration. Transport activity in Xenopus oocytes expressing PEPT1 (-) or PEPT2 (O) was measured for $10 \mathrm{~min}$ of incubation, at $\mathrm{pH} 6.0$, in the presence of ${ }^{3} \mathrm{H}$-ALA $\left(10 \mu \mathrm{Ci} \cdot \mathrm{ml}^{-1}\right)$ and increasing concentrations of unlabeled substrate (0.001-5 mM). Uptake rates in oocytes injected with water were subtracted. Uptake rates represent the mean \pm SEM for 8-10 oocytes per condition and are representative for at least two similar experiments. (b) Transport rates were transformed according to Eadie-Hofstee and kinetic constants were derived by linear regression analysis by the least-squares method $\left(\mathrm{r}^{2}\right.$, 0.982 for PEPT1 and 0.989 for PEPT2). (c) $\mathrm{pH}$ dependence of ALA uptake. Uptake of $5 \mu \mathrm{M}^{3} \mathrm{H}$-ALA $\left(10 \mu \mathrm{Ci} \cdot \mathrm{ml}^{-1}\right)$ into Xenopus oocytes expressing PEPT1 or PEPT2 was measured for $10 \mathrm{~min}$ of incubation at different $\mathrm{pH}$ values ( $\mathrm{pH}$ 5.0-8.0). Corresponding uptake rates of ${ }^{3} \mathrm{H}$-ALA into oocytes injected with water were subtracted. Data are expressed as increase in influx above flux observed at $\mathrm{pH}$ 8.0. (d) ALA uptake as a function of increasing concentration of Gly-L-Gln. Uptake of $5 \mu \mathrm{M}$ ${ }^{3} \mathrm{H}$-ALA $\left(10 \mu \mathrm{Ci} \cdot \mathrm{ml}^{-1}\right)$ into oocytes was measured for $10 \mathrm{~min}$ of incubation, at $\mathrm{pH}$ 6.0 , in the presence of increasing concentrations (0.001-1 mM) of Gly-L-Gln. Uptake rates in oocytes injected with water were subtracted. Data are presented for the residual uptake rates at the indicated concentration of Gly-L-Gln as percentage of control uptake in the absence of competitor. The $\mathrm{EC}_{50}$ values were derived by the least-squares method based on a competition curve with one component $\left(\mathrm{r}^{2}, 0.978\right.$ in case of PEPT1; and $\mathrm{r}^{2}, 0.953$ in case of PEPT2). 


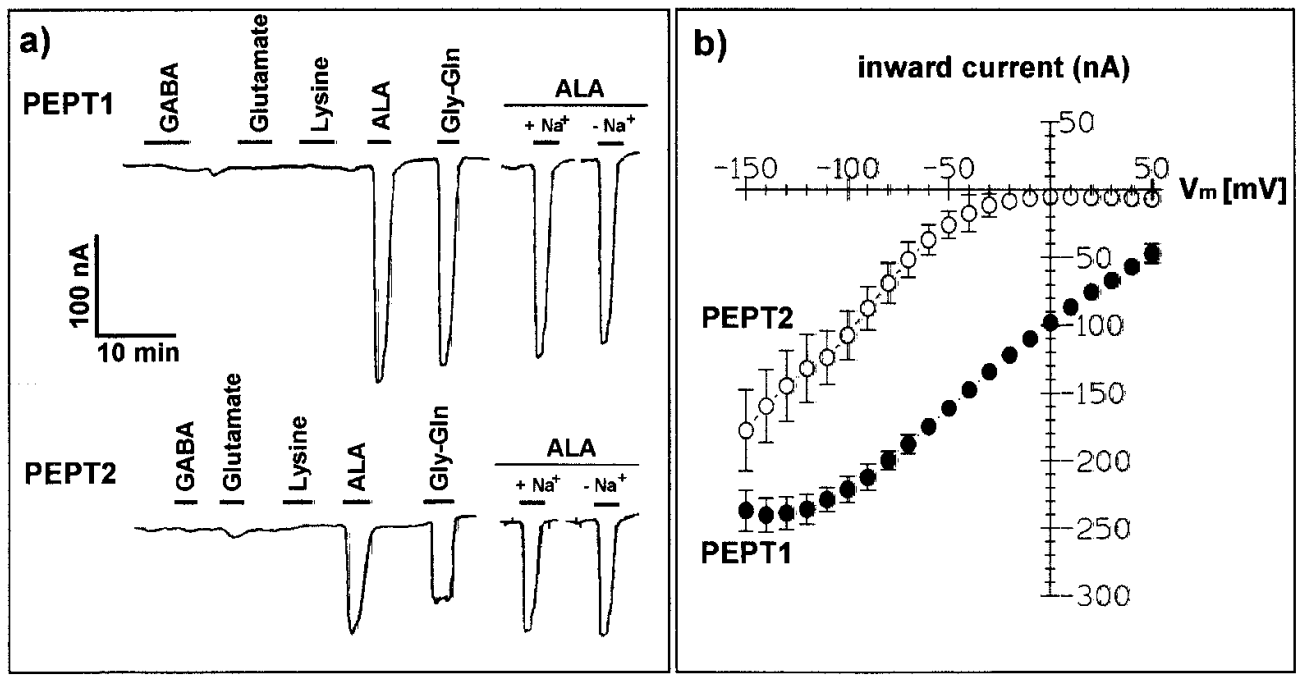

Figure 3. Recordings of ALAinduced inward currents and I-V relationships in Xenopus oocytes expressing PEPT1 or PEPT2. (a) Recordings of inward currents in oocytes expressing PEPT1 or PEPT2 in the presence of 2.5 mM GABA, lysine, glutamate, ALA or Gly-L-Gln. Oocytes were perfused with $\mathrm{Na}^{+}$-containing buffers at $\mathrm{pH}$ 6.0. The $\mathrm{Na}^{+}$ dependency of currents was studied by replacing $100 \mathrm{mM}$ $\mathrm{NaCl}\left(+\mathrm{Na}^{+}\right)$by $100 \mathrm{mM}$ CholineCl $\left(-\mathrm{Na}^{+}\right)$at membrane potentials of $-60 \mathrm{mV}$ in the presence of $2.5 \mathrm{mM}$ ALA. Control oocytes (water injected) did not show any response in inward current to the addition of GABA, lysine, glutamate,

ALA, or Gly-L-Gln. (b) Steady-state I-V relationships, as measured by the two-electrode voltage clamp technique in oocytes expressing PEPT1 or PEPT2 superfused with buffer $\mathrm{pH} 6.0$ (2.5 mM ALA) and membrane potential, held at $-60 \mathrm{mV}$. Membrane potential was then stepped symmetrically to the test potentials shown and substrate-dependent currents were obtained as the difference measured in the absence and presence of $2.5 \mathrm{mM}$ ALA. Data are presented as means \pm SEM for repeated measurements in two batches oocytes.

\section{Discussion}

ALA transport mediated by the mammalian intestinal and renal peptide transporters PEPT1 and PEPT2 was characterized by flux studies with radiolabeled ALA and dipeptides as well as by electrophysiological techniques. We unequivocally demonstrate: (a) that both mammalian peptide transporters do accept ALA as a substrate with similar affinities, $(b)$ that ALA uptake occurs by $\mathrm{pH}$ gradient-dependent electrogenic cotransport, and $(c)$ that ALA transport is shared by di- and tripeptides, and selected aminocephalosporin antibiotics, but not by its structurally related but shorter analogue GABA, nor by porphobilinogen or amino acids with a similar backbone length such as lysine or glutamate.

The rationale for using two expression systems was based on observations that the Km values for PEPT1- and PEPT2mediated fluxes depend on a variety of variables (mainly membrane potential and $\mathrm{pH}$ ) and, consequently, on the expression system. In addition, it has recently been shown that there is a protein in eukaryotic cells that may modify the $\mathrm{pH}$ dependence of PEPT1 (26) and therefore the use of one expression system may be crucial with respect to conclusions drawn on a generalized transport phenomenon. Moreover, there are examples that a single expression system may produce artificial results as shown for the rBAT transporter (27, 28 ). When its cRNA is injected into ooyctes, it induces a system B-like electrogenic exchange activity for neutral and cationic amino acids in oocytes, whereas the rBAT-cDNA when transfected into HeLa cells or COS cells did not induce any transport activity due to the lack of an an endogenous transporter subunit. For these reasons, we used two different expression systems and different transport assays to study ALA transport by the same transporters, but in cells with different genetic backgrounds.

Although the general characteristics of ALA influx were found to be independent of the expression system used, there were small differences in the $\mathrm{pH}$ optimum of flux in oocytes and $P$. pastoris cells. However, ALA affinity for interaction with the substrate-binding sites of PEPT1 and PEPT2 was almost identical irrespective of the extracellular $\mathrm{pH}$ values used in the two expression systems. This is in agreement with previous studies on transport of dipeptides and $\beta$-lactams $(1,2,9$, $10,12)$ and appears to apply in general to all transporter substrates as long as they do not carry a net charge in a $\mathrm{pH}$ range of 5.5-7.0. Therefore, for neutral compounds such as ALA, extracellular $\mathrm{pH}$ only alters the maximal transport rate, not the affinity.

Demonstration of ALA transport by mammalian peptide transporters is a novel finding with a number of physiological and pharmacological implications. As such could be considered: $(a)$ defining a new physiological role of peptide transporters, (b) addressing their pharmacological importance in treatment of epithelial tumors by photodynamic therapy based on ALA administration, $(c)$ a possible involvement in the renal handling of ALA during lead intoxication with respect to the increases in renal ALA elimination, and $(d)$ providing new insights into structural requirements for substrate recognition by the substrate-binding sites of PEPT1 and PEPT2.

The primary physiological role of intestinal and renal peptide transporter is to mediate amino acid uptake in peptidebound form (for review see 29 and 30). In addition, it has been shown that orally active $\beta$-lactam antibiotics of the cephalosporin and penicillin classes also use PEPT1 and PEPT2 for uptake into intestinal and reuptake into renal epithelial cells. We demonstrate here that the both transporters can also transport ALA. Although dietary-derived ALA may not play a significant role as a precursor for porphyrin synthesis, the capability of PEPT1 to transport ALA can explain the good bioavailability of ALA when it is adminstered orally. Providing ALA by the oral route causes significant increases in the concentration of ALA and porphyrins in peripheral tissues and plasma $(17,21)$. 
Circulating ALA is filtered in the glomerulum and it has been shown that there is efficient renal reabsorption that leads to a high cellular accumulation of ALA in renal epithelial cells $(24,25)$. Here we provide direct evidence for a role of PEPT2 in this renal reabsorption mechanism. Energized by the proton motive force, PEPT2 can transport ALA electrogenically in a dose-dependent manner back into epithelial cells of the proximal tubule.

Photodynamic therapy of neoplastic tissues including epithelial cells of the lung, colon, urinary bladder, and mammary gland uses the accumulation of porphyrins after administration of ALA to induce tissue necrosis and/or apoptosis upon photoactivation of porphyrins $(17,18)$. To determine whether ALA uptake occuring in these tissues could be due to the presence of either PEPT1 and/or PEPT2, we used RT-PCR to screen rabbit tissues for the presence of the mRNA messages of each transporter form. As shown in Fig. 4, PEPT1-specific fragments were detected almost exclusively in the small intestine, whereas the PEPT2-specific fragments were found not only in kidney but also in lung, brain, mammary gland, and, with generally weaker signals, also in a variety of other tissues. Although the physiological significance of the expression of the PEPT2 mRNA in tissues besides kidney has to be established, the distribution of the PEPT2 message corresponds well with the functional evidence on porphyrin accumulation in these organs after administration of ALA. Using PEPT2-specific antibodies and transport studies with membrane preparations could provide direct evidence for the presence of the PEPT2 protein and its contribution to uptake of ALA in these tissues. Previous studies, applying in situ hybridization of mRNA distribution of PEPT2 in rabbit and human brain, show that the message abundance is restricted to neuronal cells and the epithelium of the choroid plexus (31). This distribution matches again with the observation that autoradiography performed in brain tissues after in vitro administration of radiolabeled ALA in rats showed uptake of ALA into the brain only in restricted areas such as the choroid plexus but not at the blood brain barrier nor into the neuronal tissue (32). In contrast, isolated neurons in primary culture were capable of accumulating ALA and, subsequently, also porphyrins when ALA was provided in the culture medium (33). PEPT2 in the brain could therefore contribute to the intraorgan metabolism of ALA and the proposed cytotoxic activity of ALA in neuronal tissues (32).

Because increased ALA excretion into urine is considered a specific marker for assessing lead intoxication in animals and humans $(34,35)$, our studies identify at least one transport system involved in ALA reabsorption that could be impaired by lead exposure. It is interesting to note that previous studies in renal brush border membrane vesicles have established the kidney peptide transporter as a target for modification by heavy metals (36). This susceptibility of the renal peptide transporter to inhibition by heavy metals may explain that renal ALA homeostasis is altered during lead intoxication with a significant increase in the renal loss of ALA after glomerular filtration due to reduced reabsorption via PEPT2.

Although a number of studies have focused on determining the structural requirements for substrate recognition and affinity for binding to PEPT1 and PEPT2 $(29,30)$, we demonstrate for the first time that a molecule not possessing any peptide bond is transported electrogenically as a high affinity substrate by both epithelial peptide transporters. Based on the data of the competition experiments, only dipeptides, tripeptides, and aminocephalosporin antibiotics (all known substrates) compete with ALA at the substrate-binding domains of the transporters. Neither free amino acids, such as glutamate or lysine, generated detectable inward currents in oocytes expressing PEPT1 or PEPT2. This confirms earlier observations that free amino acids do not serve as substrates of peptide transporters in intestine and kidney $(29,30)$. The fact that the structurally related analogue $\gamma$-aminobutyric acid, which has a shorter backbone than ALA, is also not transported by PEPT1 and PEPT2 demonstrates the requirement of equal or more than four carbon units in the backbone of the transporter's substrates between the amino- and carboxy-terminal head groups. This corresponds to the backbone length as realized in normal dipeptides. It has been shown recently that the peptide bond in a dipeptide can be replaced by a ketomethylene function, as present in ALA, without loss of substrate affinity for the renal peptide transporter by use of arphamenins, a group of peptide hydrolase inhibitors (37). Similarly, arphamenin A has recently been proposed to serve as a substrate of PEPT1 in human Caco-2 cells (38). Transport of ALA by PEPT1 and PEPT2 establishes that the carbonyl function at the $\gamma$ carbon of ALA corresponding to the position of the carbonyl function in a normal dipeptide is sufficient (besides the amino and carboxy group) for recognition as a substrate. Moreover, the side chains, present in normal dipeptides, are also obviously not important for the interaction with the substrate-binding sites.

As a summary, we provide direct evidence for transport of ALA by the intestinal and renal peptide transporters at the

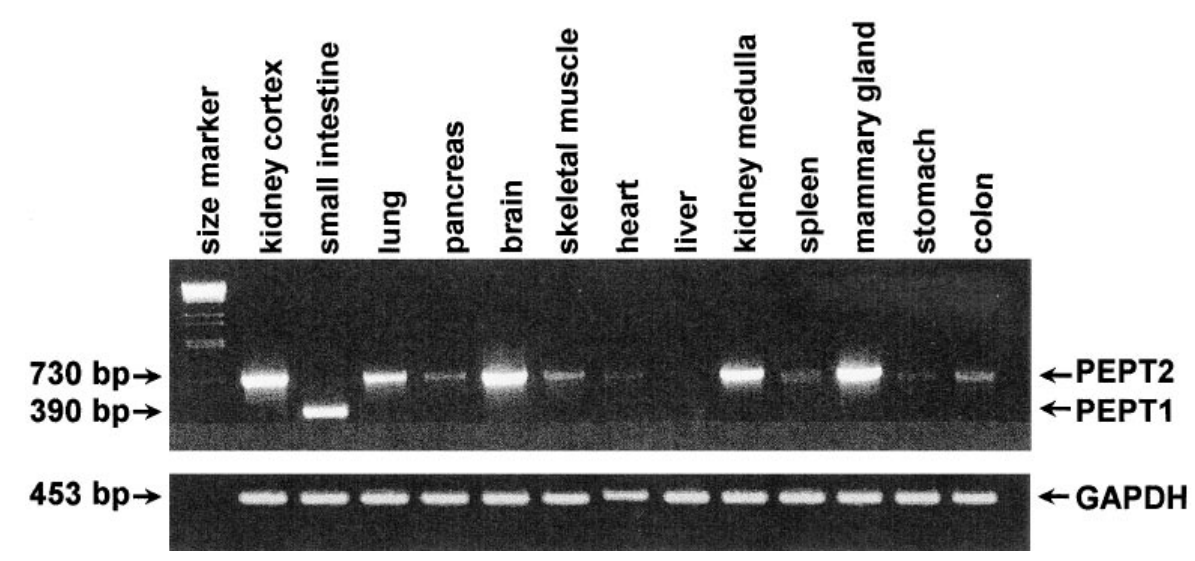

Figure 4. Expression of PEPT1 and PEPT2 mRNA in different tissues. $5 \mu \mathrm{g}$ of total RNA from rabbit kidney cortex, small intestine, lung, pancreas, brain, skeletal muscle, heart, liver, kidney medulla, spleen, mammary gland, stomach, and colon were subjected to RT-PCR using primer pairs specific for PEPT1, PEPT2, or GAPDH. The RT-PCR products were separated by agarose gel electrophoresis and visualized with ethidium bromide. 
molecular and cellular level. ALA is similar to di- and tripeptides transported by proton gradient-dependent electrogenic mechanisms. On the structural basis, ALA can serve as a substrate because it mimics a dipeptide in which the peptide bond is replaced by a ketomethylene function. Handling of ALA by the peptide transporter PEPT1 and PEPT2 does have physiological as well as pharmacological and toxicological implications for photodynamic therapy approaches based on ALAinduced porphyrin accumulation in specific tissues, and with respect to the impaired renal reabsorption of ALA during lead intoxication.

\section{Acknowledgments}

This study was supported by the Deutsche Forschungsgemeinschaft, Projekt B12, SFB 249 to H. Daniel. S. Amasheh is a recipient of a fellowship of the H. Wilhelm Schaumann Stiftung.

\section{References}

1. Boll, M., D. Markovich, W.-M. Weber, H. Korte, H. Daniel, and H. Murer. 1994. Expression cloning of a cDNA from rabbit small intestine related to proton-coupled peptide transporter. Pflueg. Arch. Eur. J. Physiol. 429:146-149.

2. Boll, M., M. Herget, M. Wagener, W.-M. Weber, D. Markovich, J. Biber, W. Clauss, H. Murer, and H. Daniel. 1996. Expression cloning and functional characterization of the kidney cortex high-affinity proton-coupled peptide transporter. Proc. Natl. Acad. Sci. USA. 93:284-289.

3. Fei, Y.-J., Y. Kanai, S. Nussberger, V. Ganapathy, F.H. Leibach, M.F. Romero, S.K. Singh, W.F. Boron, and M.A. Hediger. 1994. Expression cloning of a mammalian proton-coupled oligopeptide transporter. Nature. 368:563-566.

4. Liang, R., Y.-J. Fei, P.D. Prasad, S. Ramamoorthy, H. Han, T.L. YangFeng, M.A. Hediger, V. Ganapathy, and F.H. Leibach. 1995. Human intestinal $\mathrm{H}^{+}$/peptide cotransporter. J. Biol. Chem. 270:6456-6463.

5. Liu, W., R. Liang, S. Ramamoorthy, Y.-J. Fei, M.E. Ganapathy, M.A. Hediger, V. Ganapathy, and F.H. Leibach. 1995. Molecular cloning of PEPT2, a new member of the $\mathrm{H}^{+}$/peptide cotransporter family, from human kidney. Biochem. Biophys. Acta. 1235:461-466.

6. Saito, H., M. Okuda, T. Terada, S. Sasaki, and K.I. Inui. 1995. Cloning and characterization of a rat $\mathrm{H}+$ /peptide cotransporter mediating absorption of $\beta$-lactam antibiotics in the intestine and kidney. J. Pharmacol. Exp. Ther. 275: 1631-1637.

7. Miyamoto, K.I., T. Shiraga, K. Morita, H. Yamamoto, H. Haga, Y. Taketani, I. Tamai, Y. Sai, A. Tsuji, and E. Takeda. 1996. Sequence, tissue distribution and developmental changes in rat intestinal oligopeptide transporter. Biochim. Biophys. Acta. 1305:34-38.

8. MacKenzie, B. , D.D.F. Loo, Y.-J. Fei, W. Liu, V. Ganapathy, F.H. Leibach, and E.M. Wright. 1996. Mechanismus of the human intestinal $\mathrm{H}^{+}$-coupled oligopeptide transporter hPepT1. J. Biol. Chem. 271:5430-5437.

9. Amasheh, S., U. Wenzel, M. Boll, D. Dorn, W.-M. Weber, W. Clauss, and H. Daniel. 1997. Transport of charged dipeptides by the intestinal $\mathrm{H}^{+} /$peptide symporter PepT1 expressed in Xenopus laevis oocytes. J. Membrane Biol. 155:247-256.

10. Amasheh, S., U. Wenzel, W.-M. Weber, W. Clauss, and H. Daniel. 1997. Electrophysiological analysis of the function of the mammalian renal peptide transporter expressed in Xenopus laevis oocytes. J. Physiol. 504:169-174.

11. Nussberger, S., A. Steel, D. Trotti, M.F. Romero, W.F. Boron, and M.A. Hediger. 1997. Symmetry of $\mathrm{H}^{+}$binding to the intra- and extracellular side of the $\mathrm{H}^{+}$-coupled oligopeptide cotransporter PepT1. J. Biol. Chem. 272:77777785 .

12. Döring, F., S. Theis, and H. Daniel. 1997. Expression and functional characterization of the mammalian intestinal peptide transporter PepT1 in the methylotropic yeast P. pastoris. Biochem. Biophys. Res. Commun. 232:656-662.

13. Steiner, H.-Y., F. Naider, and J.M. Becker. 1995. The PTR family: a new group of peptide transporters. Mol. Microbiol. 16:825-834.

14. Elliott, T. 1993. Transport of 5-aminolevulinic acid by the dipeptide permease in Salmonella typhimurium. J. Bacteriol. 175:325-331.
15. Verkamp, E., V.M. Backman, J.M. Bjornsson, D. Soll, and G. Eggertsson. 1993. The periplasmic dipeptide permease system transports 5-aminolevulinic acid in Escherichia coli. J. Bacteriol. 175:1452-1456.

16. Bermudez Moretti, M., S. Correa Garcia, E. Ramos, and A. Batlle. 1996. Delta-Aminolevulinic acid uptake is mediated by the $\gamma$-aminobutyric acid-specific permease UGA 4. Cell. Mol. Biol. 42:519-523.

17. Peng, Q., T. Warloe, K. Berg, J. Moan, M. Kongshaug, K.E. Giercksky, and J.M. Nesland. 1997. 5-Aminolevulinic acid-based photodynamic therapy. Clinical research and future challanges. Cancer. 79:2282-2308.

18. Fromm, D., D. Kessel, and J. Webber. 1996. Feasibility of photodynamic therapy using endogenous photosensitization for colon concer. Arch. Surg. 131:667-669.

19. Gibson, S.L., J.J. Havens, T.H. Foster, and R. Hilf. 1997. Time-dependent intracellular accumulation of delta-aminolevulinic acid, induction of porphyrin synthesis and subsequent phototoxicity. Photochem. Photobiol. 65:416-421.

20. Steinbach, P., H. Weingandt, R. Baumgartner, M. Kriemair, F. Hofstadter, and R. Knuchel. 1995. Cellular fluorescence of the endogenous photosensitizer protoporphyrin IX following exposure to 5-aminolevulinic acid. Photochem. Photobiol. 62:887-895.

21. Loh, C.S., A.J. MacRobert, J. Bedwell, J. Regula, N. Krasner, and S Bown. 1993. Oral versus intravenous administration of 5-aminolaevulinic acid for photodynamic therapy. Br. J. Cancer. 68:41-51.

22. Webber, J., D. Kessel, and D. Fromm. 1997. Plasma levels of protoporphyrin IX in humans after oral administration of 5-aminolevulinic acid. J. Photochem. Photobiol. 37:151-153.

23. Wyss-Desserich, M.T., C.H. Sun, P. Wyss, C.S. Kurlawalla, U. Haller, M.W. Berns, and Y. Tadir. 1996. Accumulation of 5-aminolevulnic acid-induced protoporphyrin IX in normal and neoplastic human endometrial epithelial cells. Biochem. Biophys. Res. Commun. 224:819-824.

24. O'Flaherty, E.J., P.B. Hammond, and E. Tylor. 1981. Renal reabsorption and secretion of delta-aminolevulinic acid in the rat. Fundam. Appl. Toxicol. 1:278-281.

25. Cheeks, C., and R.P. Weden. 1986. Renal tubular transport of deltaaminolevulinic acid in rat. Proc. Soc. Exp. Biol. Med. 181:596-601.

26. Saito, H., Motohahi, H., Mukai, and K. Inui. 1997. Cloning and characterization of a $\mathrm{pH}$-sensing regulatory factor that modulates transport activity of the human $\mathrm{H}+/$ peptide cotransporter, PEPT1. Biochem. Biophys. Res. Commun. 237:577-582.

27. Palacin, M. 1994. A new family of proteins (rBAT and 4F2hc) involved in cationic and zwiterionic amino acid transport: a tale of two proteins in search of a transport function. J. Exp. Biol. 196:123-137.

28. Malandro, M.S., and M.S. Kilberg. 1996. Molecular biology of mammalian acid transporters. Annu. Rev. Biochem. 65:305-336.

29. Daniel, H. 1996. Function and molecular structure of brush border membrane peptide/H+ symporters. J. Membr. Biol. 154:197-203.

30. Daniel, H., and M. Herget. 1997. Cellular and molecular mechanismus of renal peptide transport. Am. J. Physiol. 273:F1-F8.

31. Nikolaus, M., U. Karbach, M. Herget, I. Rubio-Aliaga, M. Boll, H. Koepsell, and H. Daniel. 1997. Localization and suggested functional role of the oligopeptide transporter PEPT2 in the brain. 33. Int. Congr. Physiol. Sci. P010.05 (Abstr.)

32. Terr, L., and L.P. Weiner. 1983. An autoradiographic study of deltaaminolevulinic acid uptake by mouse brain. Exp. Neurol. 79:564-568.

33. Durko, I., and A. Juhasz. 1986. Porphyrin synthesis in primary nervous tissue cultures from 10(-3) M delta-aminolaevulinic acid in the presence of melatonin and neuropeptides. Neurochem. Res. 11:607-615.

34. Oishi, H., H. Nomiyama, K. Nomiyama, and K. Tomokuni. 1996. Flurometric HPLC determination of delta-aminolevulinic acid (ALA) in the plasma and urine of lead workers: biological indicators of lead exposure. J. Anal. Toxicol. 20:106-110.

35. Tomokuni, K., M. Ichiba, and Y. Hirai. 1991. Elevated urinary excretion of beta-aminoisobutyric acid and delta-aminolevulinic acid (ALA) and the inhibition of ALA-synthase and ALA-dehydratase activities in both liver and kidney in mice exposed to lead. Toxicol. Lett. 59:169-173.

36. Daniel, H., and S.A. Adibi. 1995. Selective effects of zinc on uphill transport of oligopeptides into kidney brush border membrane vesicles. FASEB (Fed. Am. Soc. Exp. Biol.) J. 9:1112-1117.

37. Daniel, H., and S.A. Adibi. 1994. Functional separation of dipeptide transport and hydrolysis in kidney brush border membrane vesicles. FASEB (Fed. Am. Soc. Exp. Biol.) J. 8:753-759.

38. Enjoh, M., K. Hashimoto, S. Arai. 1996. Inhibitory effect of arphamenine A on intestinal dipeptide transport. Biosci. Biotechnol. Biochem. 60:18931895 . 